\title{
Preparation of atomic layer deposited vanadium dioxide thin films using tetrakis(ethylmethylamino) vanadium as precursor
}

\author{
Guandong Bai, Kham M. Niang* and John Robertson \\ Department of Engineering, University of Cambridge, 9 JJ Thomson Avenue, Cambridge CB3 OFA, UK \\ ${ }^{*}$ E-mail address of corresponding author: kmn36@cam.ac.uk
}

\begin{abstract}
Vanadium dioxide $\left(\mathrm{VO}_{2}\right)$ thin films were deposited by atomic layer deposition (ALD) using tetrakis(ethylmethylamino) vanadium precursor and $\mathrm{H}_{2} \mathrm{O}$ oxidant at a temperature of $150{ }^{\circ} \mathrm{C}$. Optimization of post-deposition annealing results in smooth, continuous $\mathrm{VO}_{2}$ films (thickness, $\mathrm{t} \sim 30 \mathrm{~nm}$ ) with small grains, exhibiting a transition from semiconducting to metal phase, typically known as the metal-insulator transition (MIT), at $\sim 72{ }^{\circ} \mathrm{C}$ with a switching ratio $\sim 10^{2}$. Such films were produced with high repeatability on a wafer scale and have been successfully utilized in resistively-coupled oscillators and self-selected resistive devices. Under smaller process window, thin films $(\mathrm{t} \sim 30 \mathrm{~nm})$ with very large grains have also been produced, exhibiting the MIT ratio $\sim 10^{3}$, which is the highest achieved for the ALD $\mathrm{VO}_{2}$ films deposited on $\mathrm{SiO}_{2}$ substrates. Both types of films were characterized again after 120 days to access their stability in air, a property that was rarely investigated.
\end{abstract}

Keywords: Vanadium Dioxide; Atomic Layer Deposition; Metal Semiconductor Transition; Stability 


\section{INTRODUCTION}

Vanadium dioxide, $\mathrm{VO}_{2}$, has attracted increasing attention recently due to its remarkable metal-insulator transition (MIT) at a transition temperature $\sim 68{ }^{\circ} \mathrm{C} .{ }^{1,2}$ Recently, this material has been utilized in a wide variety of devices such as the smart windows, ${ }^{3}$ sensors, ${ }^{4}$ steepsloped devices, ${ }^{5,6}$ tunable capacitors,${ }^{7}$ optical limiting modulators, ${ }^{8}$ memory adaptive filters, ${ }^{9}$ and neuromorphic computing. ${ }^{10} \mathrm{VO}_{2}$ has been grown by various methods, including pulsed laser deposition (PLD) ${ }^{11}$ and rf magnetron sputtering. ${ }^{12}$ While PLD can produce excellent films exhibiting a MIT of more than 3 orders of magnitude, this method is limited to small substrates. On the other hand, sputtering is scalable to large area, but control of film stoichiometry is not trivial. ${ }^{13}$ Atomic layer deposition (ALD) is therefore of interest due to the control of stoichiometry arising from its self-limiting growth, its repeatability and conformality over large substrate areas. ${ }^{14}$ Even though the deposition rate is much lower in ALD than in sputtering or PLD, the thickness requirement for devices these days are increasing smaller, making the ALD method more attractive both in research and industry.

Amongst various ALD precursors that have been developed for $\mathrm{VO}_{2}$, tetrakis(ethylmethylamino) vanadium (TEMAV) has been increasingly used since it is a liquid precursor and the synthesized films mainly consist of +4 valency, leading to the growth of pure phase $\mathrm{VO}_{2}{ }^{15-20}$ Using this precursor, the window of the deposition temperatures for $\mathrm{VO}_{2}$ has been reported to be between 125 and $175^{\circ} \mathrm{C} .{ }^{15}$ The $\mathrm{VO}_{2}$ thin films were successfully deposited by $\mathrm{ALD}$ on various substrates, such as glass, $\mathrm{SiO}_{2}, \mathrm{Al}_{2} \mathrm{O}_{3}$ and $\mathrm{GaN} .{ }^{17,21-23}$ The asdeposited ALD films are amorphous due to the low deposition temperature used, without a MIT, thus a post-deposition annealing is required. Many groups have reported the optimizations of the annealing conditions (temperature, time, ambient) and have shown that the annealing conditions are very important to achieve the desired $\mathrm{VO}_{2}$ phase. ${ }^{16,17,21}$ The 
amount of MIT modulation, which is typically determined electrically or optically, depends very much on the substrates; for example, a resistivity modulation $\sim 10^{2}$ has been reported for the $\mathrm{VO}_{2}$ films deposited on $\mathrm{SiO}_{2}$ substrates, ${ }^{17,}{ }^{21}$ but a higher modulation $\sim 10^{3}$ has been reported for the $\mathrm{VO}_{2}$ films deposited on $\mathrm{GaN}$ substrates. ${ }^{22}$

One aspect that previous reports have not paid much attention to is the production of the $\mathrm{VO}_{2}$ films on a wafer scale, which is highly desirable for industry. However, it is also desirable in research community for easier incorporation of the $\mathrm{VO}_{2}$ thin films in devices, as the typical fabrication steps, such as photolithography, are easier to process using full wafers than small pieces of substrates. However, it is difficult to achieve a good uniformity using a cross-flow reactor (for example, Savannah ALD100 system from Cambridge Nanotech), especially when using precursor like TEMAV which has a very low vapour pressure $(\sim 1$ Torr at $\left.107^{\circ} \mathrm{C}\right) .{ }^{14}$

Therefore, we developed $\mathrm{VO}_{2}$ thin films by ALD and post-deposition annealing with the emphasis on using (a) larger substrates up to a 4- or 8-inch wafer, and (b) the $\mathrm{Si} / \mathrm{SiO}_{2}$ substrates that will allow possible integration onto a CMOS platform. We have recently reported that employing TEMAV multiple pulsing mode (compare to a typical single pulsing) results in thin films with a higher deposition rate and a smaller chemical consumption without compromising the thickness uniformity. ${ }^{24}$ The films we deposited have been successfully incorporated in resistively-coupled oscillators for neuromorphic application ${ }^{25,26}$ and selector devices. $^{27}$

Here, we report the optimization of the post-deposition annealing conditions, employing a quartz tube furnace for annealing of small substrates and a Fiji ALD chamber for annealing of large substrates. The structural, optical and electrical properties of the $\mathrm{VO}_{2}$ films that can be typically produced by the ALD are presented. Moreover, we also present the $\mathrm{VO}_{2}$ thin films 
which have much larger grains and higher MIT modulation than the typical films and compare the two types of films in terms of their stability in air and potential use in devices.

\section{EXPERIMENTAL DETAILS}

$\mathrm{VO}_{2}$ thin films were deposited using a cross flow reactor system (Savannah S100 ALD from Cambridge Nanotech) on various substrates, such as $\mathrm{Si}, \mathrm{SiO}_{2}$ and quartz, with various substrate sizes up to 4-inch diameter wafer. The multiple pulsing of TEMAV is done by the following sequence: (TEMAV pulse $0.02 \mathrm{~s}$-delay $2 \mathrm{~s}$ ) repeat 8 times /purge $3 \mathrm{~s} / \mathrm{H}_{2} \mathrm{O}$ pulse $0.03 \mathrm{~s} /$ purge $5 \mathrm{~s}$. The TEMAV cylinder was heated to $105^{\circ} \mathrm{C}$, yielding a vapor pressure $\sim 1$ Torr. During depositions, the chamber temperature was set to $150{ }^{\circ} \mathrm{C}$, and the pressure is 0.1 Torr which was achieved by $\mathrm{N}_{2}$ flow at 20 standard cubic centimeters per minute ( $\mathrm{sccm}$ ).

Post-deposition annealing was performed either in a 1-inch diameter quartz tube furnace (Lindberg/Blue M, Thermo Scientific) or in a Fiji F200 ALD System from Cambridge Nanotech. The following annealing parameters were varied: temperatures $\left(450\right.$ and $\left.550^{\circ} \mathrm{C}\right)$, pressures (between 8 and $150 \mathrm{~Pa})$, ambient conditions $\left(\mathrm{O}_{2}\right.$ or $\left.\mathrm{Ar} / \mathrm{O}_{2}\right)$ and annealing times (between 0.5 and 2 hours).

The structural and optical properties of the $\mathrm{VO}_{2}$ films were analyzed by room temperature Raman spectroscopy (Renishaw InVia), X-ray diffraction (Bruker D8 Advance), scanning electron microscopy (FEI Magellan 400), atomic force microscopy (Agilent 5400) and UVVis-NIR optical Spectrometry (Cary 7000). Wafer maps of the film thicknesses were obtained using spectroscopic ellipsometry (J.A. Woollam M-2000), integrated with an automated xy stage and a $75 \mathrm{~W}$ high intensity Xenon arc lamp for the spectrum of light between 0.7 to $5 \mathrm{eV}$. The film thicknesses were measured at 49 locations over a 4-inch diameter wafer. The thickness uniformity is determined by the ratio of the standard deviation over the mean value of all points taken over the wafer, multiplied by $100 \%$ and subtracted from $100 \%$. 
To determine the MIT characteristics, the van der Pauw resistivity measurements were performed using a Keithley 4200 parameter analyzer and a prober with a home-built heater/substrate holder which temperatures were varied between 25 and $120{ }^{\circ} \mathrm{C}$.

\section{RESULTS}

\section{A. Physical properties}

Raman spectroscopy is a fast, non-destructive method employed here as a preliminary test to probe the lattice vibrations in the $\mathrm{VO}_{2}$. Figure 1(a) shows the Raman scattering spectra of the $\mathrm{VO}_{2}$ films under various annealing conditions in a quartz tube furnace. Thin films annealed at $450{ }^{\circ} \mathrm{C}$ under vacuum (chamber pressure at $0.3 \mathrm{~Pa}$ ) exhibit no discernible peaks, indicating that the films are still amorphous. On the other hand, thin films annealed in air at $550{ }^{\circ} \mathrm{C}$ result in pure $\mathrm{V}_{2} \mathrm{O}_{5}$ phase, in agreement with the previous studies. ${ }^{28}$ Another source of reference for $\mathrm{V}^{5+}$ peak was obtained by the analyzing $\mathrm{V}_{2} \mathrm{O}_{3}$ powder from Alfa Aesar, before and after annealing in air at $550{ }^{\circ} \mathrm{C}$ which are also shown in Fig. 1(a). Upon annealing at $450^{\circ} \mathrm{C}$ at $5 \mathrm{~Pa}$ in $\mathrm{O}_{2}$, various peaks are observed; with the main peaks at 195, 224, 309, 399 and $616 \mathrm{~cm}^{-1}$, which can be identified as those related to $\mathrm{VO}_{2} .^{29}, 30$ The large peak at $\sim 510$ and the broad peak at $\sim 950 \mathrm{~cm}^{-1}$ are related to the silicon substrate. When the $\mathrm{O}_{2}$ pressure is increased to $100 \mathrm{~Pa}$, films with mixed phase $\left(\mathrm{VO}_{2}\right.$ and $\left.\mathrm{V}_{2} \mathrm{O}_{5}\right)$ are formed.

It appears that if a vacuum or lower $\mathrm{O}_{2}$ pressure was used, a higher temperature (up to $\sim 500{ }^{\circ} \mathrm{C}$ ) is required to produce $\mathrm{VO}_{2}$, as also shown by Zhang et al. ${ }^{18}$ The evolution of film seems to follow from amorphous to polycrystalline phases of $\mathrm{V}^{4+}$, and then $\mathrm{V}^{5+}$. It is also noted that this evolution and the annealing parameter space are very similar among films synthesized using TEMAV. ${ }^{16-18}$

As shown in Fig. 1(b), due to the temperature gradient along the length of the quartz tube, the actual area that is suitable for annealing of $\mathrm{VO}_{2}$ is rather small (the rectangular boxes measuring $\sim 2 \mathrm{~cm} \times 4 \mathrm{~cm}$ ). Therefore, for higher throughput and annealing of whole wafers, a 
Fiji ALD system, with a capacity for substrate size up to an 8-inch diameter wafer, was used. As shown in Fig. 2(a), $\mathrm{VO}_{2}$ samples $(2 \mathrm{~cm} \times 2 \mathrm{~cm}$ in size, total 9 pieces $)$ were spread over the substrate holder of the ALD system, and the films were annealed at $480{ }^{\circ} \mathrm{C}$ for 2 hours under an $\mathrm{Ar} / \mathrm{O}_{2}$ flow at 200/200 sccm at a chamber pressure of $40 \mathrm{~Pa}$. Figure 2(b) shows the Raman scattering spectra of the $\mathrm{VO}_{2}$ thin films at various positions, and the peak intensity at $616 \mathrm{~cm}^{-1}$ are shown in Fig. 2(a). Direct correlation between the peak intensity to the location of the sample is not done due to error within measurement, for example, the peak intensity will change slightly during laser warm up. However, Fig. 2 shows that the annealing was successfully performed in a Fiji ALD system for area of an 8-inch diameter wafer. The Raman peaks of $\mathrm{VO}_{2}$ and $\mathrm{V}_{2} \mathrm{O}_{5}$ from both annealing systems and those from literature are compared in Table 1, generally the Raman data between our work and others agree well. ${ }^{28-30}$

The crystallinity of the synthesized films was analyzed by XRD. In Fig. 3, both the tube furance and Fiji annealed samples show a dominant peak at $2 \theta=27.9^{\circ}$ which is the $(011)$ reflection. The thicker film also shows a smaller peak at $2 \theta=39.8$ and $57.7^{\circ}$ which are the (002) and (022) reflection (JCPDS card: 00-044-0252). These results confirm the formation of monolinic $\mathrm{VO}_{2}(\mathrm{M})$. There are other $\mathrm{VO}_{2}$ polymorphs, such as $\mathrm{VO}_{2}(\mathrm{~A}), \mathrm{VO}_{2}(\mathrm{~B})$ and $\mathrm{VO}_{2}(\mathrm{R})$. The tetragonal $\mathrm{VO}_{2}(\mathrm{R})$ is achieved upon thermal heating of $\mathrm{VO}_{2}(\mathrm{M})$ films above $68^{\circ} \mathrm{C}$. The semi-metallic $\mathrm{VO}_{2}(\mathrm{~B})$ is an intermediate phase that is formed under narrow annealing conditions. ${ }^{16,17}$ The insulating $\mathrm{VO}_{2}(\mathrm{~A})$ has rarely been reported in the ALD deposited films. However, the growth of all three polymorphs, $\mathrm{VO}_{2}(\mathrm{~A}, \mathrm{~B}$, and $\mathrm{M})$ has been demonstrated by PLD on the $\mathrm{SrTiO}_{3}$ substrates. ${ }^{36}$

\section{B. Electrical properties}

The resistivity values, $\rho$, as a function of temperature and the corresponding derivative, $\mathrm{d}(\log \rho) / \mathrm{dT}$, of the $\mathrm{VO}_{2}$ thin films after annealing in quartz tube furnace or Fiji ALD system are shown in Fig. 4(a) and (b), respectively. A clear MIT modulation by temperature, as 
shown by the low resistivity (metal) at high temperatures and high resistivity (insulator) at low temperatures, was observed. For the $\mathrm{VO}_{2}$ thin films that were subjected to tube furnace annealing (Fig. 4(a)), the transition temperature during a heating cycle, $\mathrm{T}_{\mathrm{h}}$, is $72.0{ }^{\circ} \mathrm{C}$ (transition from insulator to metal), and the transition temperature during a cooling cycle, $\mathrm{T}_{\mathrm{c}}$, is $60.3{ }^{\circ} \mathrm{C}$ (transition from metal to insulator). For the $\mathrm{VO}_{2}$ thin films that were subjected to annealing in Fiji system (Fig. 4(b)), the phase transitions occur at lower temperatures, with $\mathrm{T}_{\mathrm{h}}$ and $\mathrm{T}_{\mathrm{c}}$ at $60.5{ }^{\circ} \mathrm{C}$ and $47.5{ }^{\circ} \mathrm{C}$, respectively. From the $\mathrm{FWHM}$ of the derivative profiles, annealing in Fiji system shows a narrower phase transition. The resistivity modulation is $\sim 10^{2}$ for both types of annealing, which is in the same order as that reported by Rampelberg et al., ${ }^{17}$ who also used the $\mathrm{SiO}_{2}$ substrates. It should be noted that the resistivity modulation is dependent on the type of substrates used. An order of magnitude improvement on the resistivity modulation has been reported when the $\mathrm{VO}_{2}$ is deposited on the latticed matched GaN substrates. ${ }^{22}$

\section{Optical properties}

As shown in the inset of Fig. 5(a), the optical transmission spectrum of $\mathrm{VO}_{2}$ with thickness $\sim 30 \mathrm{~nm}$ exhibits a transmittance $\sim 50 \%$ at wavelength, $\lambda, \sim 500 \mathrm{~nm}$ (visible region) and up to $\sim 90 \%$ at $\lambda \sim 2000 \mathrm{~nm}$ (near infrared region), which are consistent with previous reports. ${ }^{31}$ The physical appearance of the films grown on quartz substrates are greyish. The optical band gap, $E_{g}$, is extracted using Tauc's method using the relation: ${ }^{32}$

$$
\alpha h v=B\left(h v-E_{g}\right)^{n},
$$

where $\alpha$ is the absorption coefficient, $h v$ is the photon energy, $E_{g}$ is the band gap, $B$ is a frequency dependent constant and $n$ is either 0.5 or 2 (direct or indirect allowed transitions). The band gap can be deduced from the intercept of the extrapolated linear part of the plot of $(\alpha h v)^{0.5}$ vs. $h v$. A smaller gap $\sim 0.55 \mathrm{eV}$ and a larger gap $\sim 1.35 \mathrm{eV}$ can be extracted (Fig. 5a), 
which are consistent with the previously reported values. ${ }^{33}$ The larger gap can be assigned to the onset of transitions from $\mathrm{O} 2 p$ to $\mathrm{V} 3 d$ states, and the smaller gap $\sim 0.55 \mathrm{eV}$ to the $d-d$ transitions in the conduction band. $2,34,35$ Another way to determine band gap is the E04 method. As shown in Fig. 5(b), at the absorption coefficient of $10^{4} \mathrm{~cm}^{-1}$, the gap is $0.65 \mathrm{eV}$, broadly in agreement with the value determined by Tauc method in Fig. 5(a).

D. Thickness uniformity and film morphology

Figure 6 shows the thickness distribution of the $\mathrm{VO}_{2}$ films over a 4-inch diameter wafer. These films were deposited using multiple pulsing of TEMAV as described in a previous paper, with a GPC of $0.06 \pm 0.02 \mathrm{~nm} \cdot{ }^{24}$ To improve the thickness uniformity, we rotated the wafer $180^{\circ}$ halfway through the deposition. A deposition of 450 ALD cycles produces a film with average thickness of $25.1 \pm 0.8 \mathrm{~nm}$ and thickness uniformity of $88.5 \%$ as shown in Fig. 6(a). Likewise, a deposition of 890 ALD cycles produces a film with average thickness of $47.7 \pm 1.0 \mathrm{~nm}$ and a slightly better uniformity of $90.3 \%$ as shown in Fig. 6(b). The uniformity achieved within-wafer uniformity up to $98 \%$ has been previously reported for $\mathrm{VO}_{2}$ deposited on a 12-inch diameter wafer. ${ }^{16}$ Such a good uniformity is possible due to efficient precursor gas distribution over the substrate through a shower head in the commercial ALD tool, the EX reactor from Tokyo Electron Limited. We showed here that a modest thickness uniformity could still be achieved using a cross flow type ALD system.

Thin films deposited by ALD are typically very smooth which is very useful for large area electronics. Amorphous $\mathrm{ALD} \mathrm{VO}_{2}$ thin films show a typical root mean square (rms) roughness of only $0.27 \mathrm{~nm}$ for a scan area of $2 \mathrm{~cm} \times 2 \mathrm{~cm}$ by the AFM (Fig. 7(a)). However, the required post-deposition annealing roughens the surface, with the emergence of polycrystallinity. Figure $7(\mathrm{~b})$ shows a $\mathrm{VO}_{2}$ thin film $(\mathrm{t} \sim 30 \mathrm{~nm})$ with a roughness rms of 2.67 nm. The SEM micrograph in Fig. 7(c) shows a smooth, continuous film with a mixture of small, round grains $(\sim 20-50 \mathrm{~nm}$ in diameter $)$ and larger elongated grains $(\sim 100-200 \mathrm{~nm}$ 
in length). The density of the film ( $\mathrm{t} \sim 25 \mathrm{~nm}$ on Si substrate) measured by X-ray reflectivity was shown to be $4.47 \mathrm{gcm}^{-3}$, which is close to the density of bulk $\mathrm{VO}_{2}$ which is $4.57 \mathrm{gcm}^{-3}$.

\section{DISCUSSION}

The smooth, continuous film with small and medium polycrystalline grains shown in Fig. 7 is of important requirement in producing $\mathrm{VO}_{2}$ phase. During the annealing optimization, we found that when the annealing temperature is too high and/or too much oxygen, the grains coalesce, and the films are no longer continuous. It also coincides with the appearance of $\mathrm{V}_{2} \mathrm{O}_{5}$ phase shown by Raman spectroscopy. On the other hand, when the temperature is too low, the film is continuous but without granular structures seen under SEM, and there is very weak or no modulation of MIT. The annealing conditions optimized for both quartz tube furnace and the Fiji ALD system are reproducible, and they consistently produce smooth $\mathrm{VO}_{2}$ films with MIT modulation $\sim 10^{2}$ (for $\mathrm{t} \sim 30 \mathrm{~nm}$ ). As shown in Fig. 4, the typical resistivity at room temperature (below MIT) is $\sim 1 \Omega \mathrm{cm}$, and it reduces to $\sim 0.01 \Omega \mathrm{cm}$ at higher temperature (above MIT).

For the annealing in quartz tube furnace, when the samples are slightly shifted towards higher temperatures from the optimized process window shown in Fig. 1(b), the annealed $\mathrm{VO}_{2}$ films consist of round grains of various sizes ( 50 to $250 \mathrm{~nm}$ in diameter) and very large, elongated grains ( 400 to $1200 \mathrm{~nm}$ in length), as shown in Fig. 8(a). The MIT characteristics of such films with large grains (LG), along with the typical films with small grains (SG), are shown in Fig. 8(b). The resistivity below MIT is similar for both LG and SG films ( $1 \Omega \mathrm{cm})$. However, above MIT, the resistivity of LG film is much lower $(\sim 0.001 \Omega \mathrm{cm})$ than that of SG film $(\sim 0.01 \Omega \mathrm{cm})$. The LG film thus exhibits MIT modulation $\sim 10^{3}$ (for $\mathrm{t} \sim 30 \mathrm{~nm}$ ). This is the highest that has been reported for the $\mathrm{VO}_{2}$ films deposited on $\mathrm{SiO}_{2}$ substrates, and on a par with films deposited on GaN substrates. ${ }^{22}$ 
To access the stability of VO2 films, the resistivity modulation was measured again after 60 days in air. As shown in Fig. 8(b) the whole resistivity profile is shifted up, and the room temperature resistivity is now $\sim 100 \Omega \mathrm{cm}$. The resistivity of films with $\mathrm{V}_{2} \mathrm{O}_{5}$ phase is generally higher than that of films with $\mathrm{VO}_{2}$ phase, and given that $\mathrm{V}^{5+}$ states are normally observed at the surface of $\mathrm{VO}_{2}$ film, therefore, it seems that oxidation to higher valence state is happening in the LG film. However, it is still predominantly $\mathrm{VO}_{2}$, as evidenced by the MIT transition and the Raman shift spectra shown in Fig. 8(b) and (c).

On the other hand, the SG film shows stability even after 120 days in air. The difference of the air stability between the LG and SG films could be attributed to the morphology of these films. It clearly shows that a porous, rugged surface of the LG film is more susceptible to the ambient (moisture, oxidation, etc.) than a dense, continuous surface of the SG film, therefore an encapsulation layer would be required. Despite its smaller MIT modulation than LG films, the SG films are more attractive for incorporation in oscillator circuits due to their scalability and compatibility to CMOS platform..$^{25,26}$

\section{CONCLUSIONS}

Optimizations of the ALD $\mathrm{VO}_{2}$ thin films deposited from TEMAV and water precursors were carried out, using different annealing systems for substrates of various sizes up to 8-inch diameter wafer. The physical, optical and electrical characteristics of the films were reported. Moreover, the $\mathrm{VO}_{2}$ thin films with very large, elongated grains showed the highest MIT modulation reported for films deposited on $\mathrm{SiO}_{2}$ substrates. However, the films with smaller grains and modest MIT modulation have a smooth continuous surface, and they are promising for integration in devices and circuits. Moreover, these films are found to be very stable in air. 


\section{ACKNOWLEDGMENT}

The financial support from the European Union's Horizon 2020 research and innovation program PHASE-CHANGE SWITCH (grant agreement no. 737109) is acknowledged. 


\section{REFERENCES}

1. $\quad$ F. J. Morin, Phys. Rev. Lett. 3, 34 (1959).

2. $\quad$ H. W. Verleur, A. S. Barker and C. N. Berglund, Phys. Rev. 172, 788 (1968).

3. I. Hamberg and C. G. Granqvist, J. Appl. Phys. 60, 123 (1986).

4. B. Hu, Y. Ding, W. Chen, D. Kulkarni, Y. Shen, V. V. Tsukruk and Z. L. Wang, Adv. Mater. 22, 5 (2010)

5. G. Stefanovich, A. Pergament and D. Stefanovich, J. Phys.: Condens. Matter 12, 8837 (2000).

6. W. A. Vitale, C. F. Moldovan, M. Tamagnone, A. Paone, A. Schuler and A. M. Ionescu, IEEE Electron Device Lett. 36, 972 (2015).

7. W. A. Vitale, L. Petit, C. F. Moldovan, M. Fernández-Bolaños, A. Paone, A. Schüler and A. M. Ionescu, Sens. Actuator A : Physcal 241, 9 (2016).

8. M. Maaza, D. Hamidi, A. Simo, T. Kerdja, A. K. Chaudhary and J. B. K. Kana, Opt. Commun. 285, 4 (2012).

9. T. Driscoll, H.-T. Kim, B.-G. Chae, M. Di Ventra and D. N. Basov, Appl. Phys. Lett. 95, 043503 (2009).

10. Y. Zhou and S. Ramanathan, Proceedings of the IEEE 103, 1289 (2015).

11. C.-Y. Kim, S. H. Kim, S. J. Kim and K.-S. An, Appl. Surf. Sci. 313, 368 (2014).

12. Y. Shigesato, M. Enomoto and H. Odaka, Jpn. J. Appl. Phys. 39, 6016 (2000).

13. H.-N. Cui, V. Teixeira, L.-J. Meng, R. Wang, J.-Y. Gao and E. Fortunato, Thin Solid Films 516, 1484 (2008).

14. V. P. Prasadam, N. Bahlawane, F. Mattelaer, G. Rampelberg, C. Detavernier, L. Fang, Y. Jiang, K. Martens, I. P. Parkin and I. Papakonstantinou, Mater. Today Chem. 12, 396 (2019).

15. T. Blanquart, J. Niinistö, M. Gavagnin, V. Longo, M. Heikkilä, E. Puukilainen, V. R. Pallem, C. Dussarrat, M. Ritala and M. Leskelä, RSC Adv. 3, 1179 (2013).

16. P. A. Premkumar, M. Toeller, I. P. Radu, C. Adelmann, M. Schaekers, J. Meersschaut, T. Conard and S. V. Elshocht, ECS J. Solid State Sci. Technol. 1, P169 (2012).

17. G. Rampelberg, D. Deduytsche, B. De Schutter, P. A. Premkumar, M. Toeller, M. Schaekers, K. Martens, I. Radu and C. Detavernier, Thin Solid Films 550, 59 (2014).

18. K. Zhang, M. Tangirala, D. Nminibapiel, W. Cao, V. Pallem, C. Dussarrat and H. Baumgart, ECS Transactions 50, $175(2013)$

19. A. P. Peter, K. Martens, G. Rampelberg, M. Toeller, J. M. Ablett, J. Meersschaut, D. Cuypers, A. Franquet, C. Detavernier, J.-P. Rueff, M. Schaekers, S. Van Elshocht, M. Jurczak, C. Adelmann and I. P. Radu, Adv. Funct. Mater. 25, 679 (2015).

$20 . \quad$ A. C. Kozen, H. Joress, M. Currie, V. R. Anderson, C. R. Eddy and V. D. Wheeler, J. Phys. Chem. C 121, 19341 (2017).

21. $\quad$ X. Lv, Y. Cao, L. Yan, Y. Li and L. Song, Appl. Surf. Sci. 396, 214 (2017).

22. B. P. Downey, V. D. Wheeler and D. J. Meyer, Appl. Phys. Express 10, 061101 (2017).

23. P. Dagur, A. U. Mane and S. A. Shivashankar, J. Crystal Growth 275, e1223 (2005).

24. K. M. Niang, G. Bai and J. Robertson, J. Vac. Sci. Technol. A 38, 042401 (2020).

25. E. Corti, B. Gotsmann, K. E. Moselund, A. M. Ionescu, J. Robertson and S. Karg, Solid State Electron. 168 107729 (2020).

26. E. Corti, A. Khanna, K. Niang, J. Robertson, K. E. Moselund, B. Gotsmann, S. Datta and S. Karg, IEEE Electron Device Lett. 41, 629 (2020).

27. Z. Wang, J. Kang, G. Bai, G. Zhong, B. Wang, Z. Yu, Y. Ling, Q. Chen, L. Bao, L. Wu, Y. Cai, J. Robertson and R. Huang, IEEE Electron Device Lett. 41, 1009 (2020).

28. J. Janicskó-Csáthy, A. Nagy, L. Nánai, W. Marine, S. P. Souto, M. Balkanski and T. F. George, J. Mater. Res. 17, 1096 (2011)

29. M. Pan, J. Liu, H. Zhong, S. Wang, Z.-f. Li, X. Chen and W. Lu, J. Crystal Growth 268, 178 (2004).

30. P. Schilbe, Phys. B 316, 600 (2002).

31. Z. Chen, Y. Gao, L. Kang, J. Du, Z. Zhang, H. Luo, H. Miao and G. Tan, Sol. Energy Mater Sol. Cells 95, 8 (2011).

32. J. Tauc, R. Grigorovici and A. Vancu, Phys. Status Solidi 15, 627 (1966).

33. T. J. Huffman, C. Hendriks, E. J. Walter, J. Yoon, H. Ju, R. Smith, G. L. Carr, H. Krakauer and M. M. Qazilbash, Phys. Rev. B 95, 075125 (2017).

34. H. Lu and J. Robertson, Phys. Status Solidi B 256, 1900210 (2019).

35. H. Lu, Y. Guo and J. Robertson, Phys. Rev. Mater. 3, 094603 (2019).

36. A. Srivastava, H. Rotella, S. Saha, B. Pal, G. Kalon, S. Mathew, M. Motapothula, M. Dykas, P. Yang, E. Okunishi, D.D. Sarma, and T.Venkatesan, APL Materials 3, 026101 (2015). 
Table 1. Comparison of Raman peaks of the polycrystalline $\mathrm{VO}_{2}$ and $\mathrm{V}_{2} \mathrm{O}_{5}$ films between this work and other works.

\begin{tabular}{|c|c|c|c|c|c|}
\hline \multirow{2}{*}{\multicolumn{2}{|c|}{ This work }} & \multirow{3}{*}{$\begin{array}{l}\text { VO2 } \\
\text { Pan [29] }\end{array}$} & \multirow{3}{*}{ Schilbe [30] } & \multicolumn{2}{|c|}{ 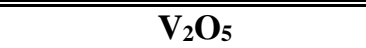 } \\
\hline & & & & This work & Janicsko- \\
\hline $\begin{array}{c}\text { Tube } \\
\text { furnace }\end{array}$ & $\begin{array}{c}\text { Fiji } \\
\text { system }\end{array}$ & & & & \\
\hline 141 & 138 & -- & 149 & 103 & 104 \\
\hline 195 & 194 & 194 & 199 & 145 & 149 \\
\hline 224 & 222 & 225 & 225 & 197 & 197 \\
\hline 261 & 257 & 258 & 259 & 284 & 285 \\
\hline-- & -- & 265 & 265 & 304 & 305 \\
\hline 309 & 304 & 308 & 313 & 404 & 405 \\
\hline 339 & 338 & 339 & 339 & 481 & 482 \\
\hline 388 & 391 & 392 & 392 & 527 & 528 \\
\hline 399 & -- & 395 & 395 & -- & 628 \\
\hline 439 & 438 & 444 & 444 & 651 & 652 \\
\hline-- & -- & 453 & 453 & 701 & 702 \\
\hline-- & -- & 489 & 489 & & 804 \\
\hline 497 & -- & 503 & 503 & 995 & 995 \\
\hline 583 & -- & 585 & 595 & 1020 & 1020 \\
\hline 616 & 616 & 618 & 618 & & \\
\hline 667 & -- & 650 & 670 & & \\
\hline 824 & 823 & 825 & 830 & & \\
\hline
\end{tabular}


FIG. 1. (a) Raman spectra of $\mathrm{VO}_{2}$ thin films annealed under various annealing conditions in a quartz tube furnace, and (b) the temperature distribution measured across furnace for different setpoints. The red squares are where the $\mathrm{VO}_{2}$ samples were placed during annealing.

FIG. 2. (a) The positions of the $\mathrm{VO}_{2}$ samples placed across the 8-inch diameter substrate holder of a Fiji S200 ALD system for annealing at $450{ }^{\circ} \mathrm{C}$ for 2 hours in $\mathrm{Ar} / \mathrm{O}_{2}(100 / 100$ sccm), and (b) Raman spectra of the $\mathrm{VO}_{2}$ thin films located at various positions shown in (a). The peak intensity for the Raman shift at $616 \mathrm{~cm}^{-1}$ are also shown in (a).

FIG. 3. Comparison of the XRD profiles of the $\mathrm{VO}_{2}$ thin films annealed in either quartz tube furnce or Fiji ALD chamber. Peaks marked with * seem to be due to measurement artefact or substrate related.

FIG. 4. Resistivity, $\rho$, as a function of temperature and its derivative $(d(\log \rho) / d T)$ for the annealed $\mathrm{VO}_{2}(\mathrm{t} \sim 30 \mathrm{~nm})$ thin films annealed in (a) quartz tube furnce and (b) Fiji ALD chamber. The transition temperatures during heating cycle $\left(\mathrm{T}_{h}\right)$ and cooling cycle $\left(\mathrm{T}_{\mathrm{c}}\right)$ are also shown.

FIG. 5. (a) Transmittance (inset) and Tauc plot of absorption for a $\mathrm{VO}_{2}$ film ( $\mathrm{t} \sim 30 \mathrm{~nm}$ ). The smaller gap $(0.55 \mathrm{eV})$ can be assigned due to the $d$ - $d$ transitions, and the larger gap $(1.3 \mathrm{eV})$ is due to $\mathrm{O} 2 p$ to $\mathrm{V} 3 d$ transitions. (b) Absorption coefficient as a function of energy for the same film.

FIG. 6. Thickness distribution for $\mathrm{VO}_{2}$ films after (a) 450 ALD cycles, and (b) 890 ALD cycles. To achieve good uniformity, the wafers were rotated by $180^{\circ}$ halfway through the deposition. The gas inlet and outlet of the cross flow reactor are shown in the map.

FIG. 7. AFM micrographs of the $\mathrm{VO}_{2}$ film $(\mathrm{t} \sim 30 \mathrm{~nm})$ (a) before and (b) after annealing, the rms of roughness are also shown. (c) SEM micrograph of the polycrystalline $\mathrm{VO}_{2}$ film of same thickness. The scale bar in each image is $500 \mathrm{~nm}$.

FIG. 8. (a) SEM micrograph of the $\mathrm{VO}_{2}$ thin film $(\mathrm{t} \sim 30 \mathrm{~nm})$ with large grains (LG). The scale bar in SEM image is $500 \mathrm{~nm}$. (b) Resistivity vs. temperature plots of the $\mathrm{VO}_{2}$ films with LG and small grains (SG), measured as fresh sample and after 60 or 120 days. (c) Raman shift spectra of the LG film measured after 60 days. 

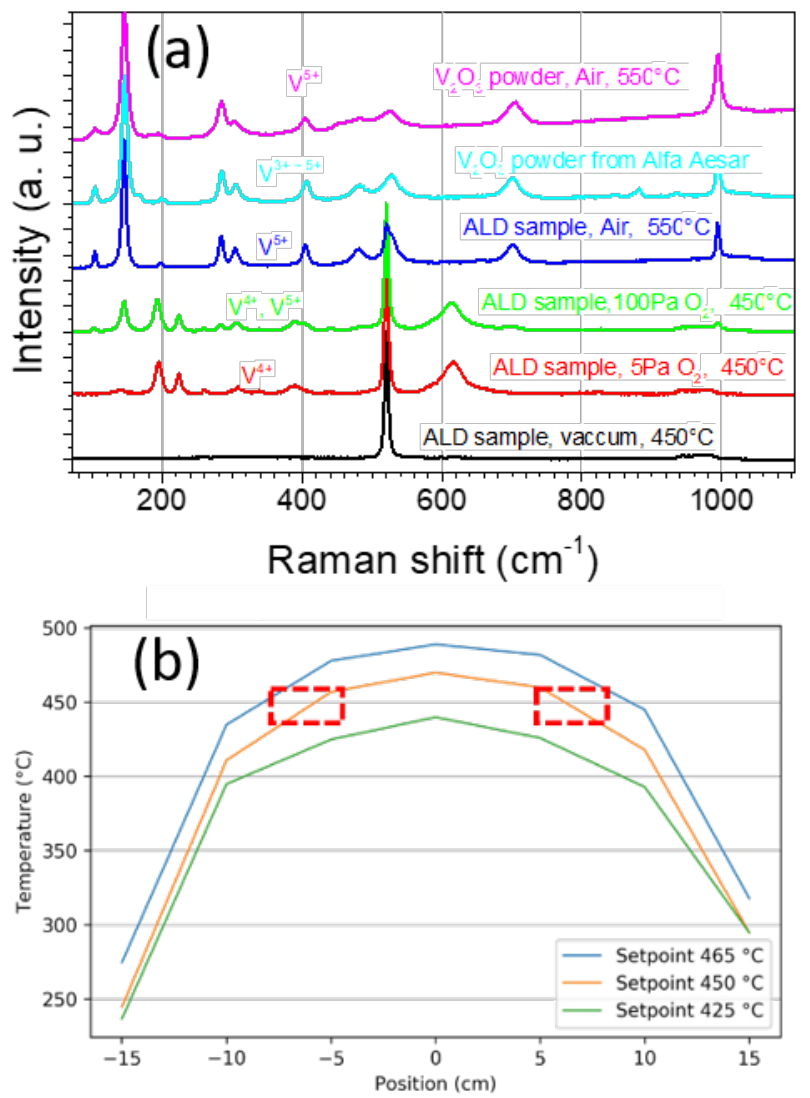


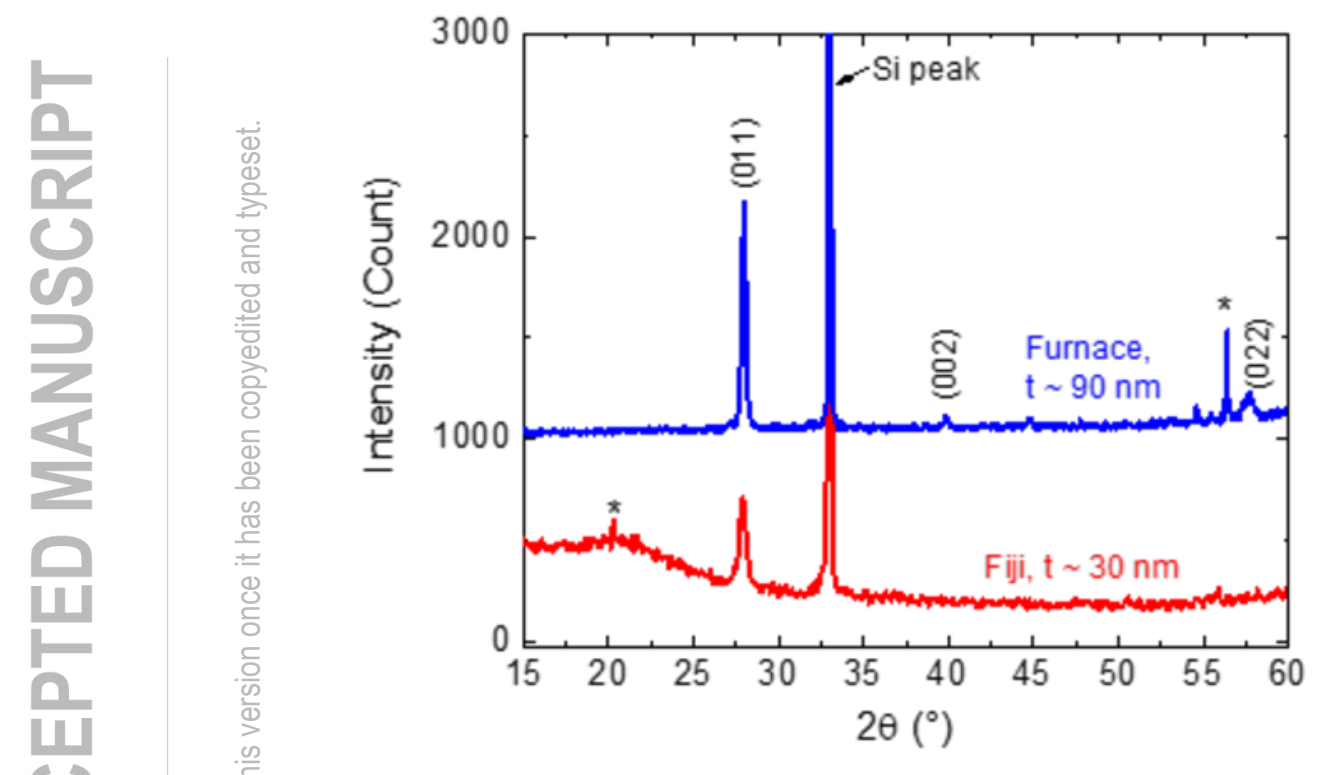

$+$

员

8 응

疍

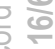

농

듬

15

年

플

证

단

기ㄹㅗㅛ

오 틀

응응

崖 

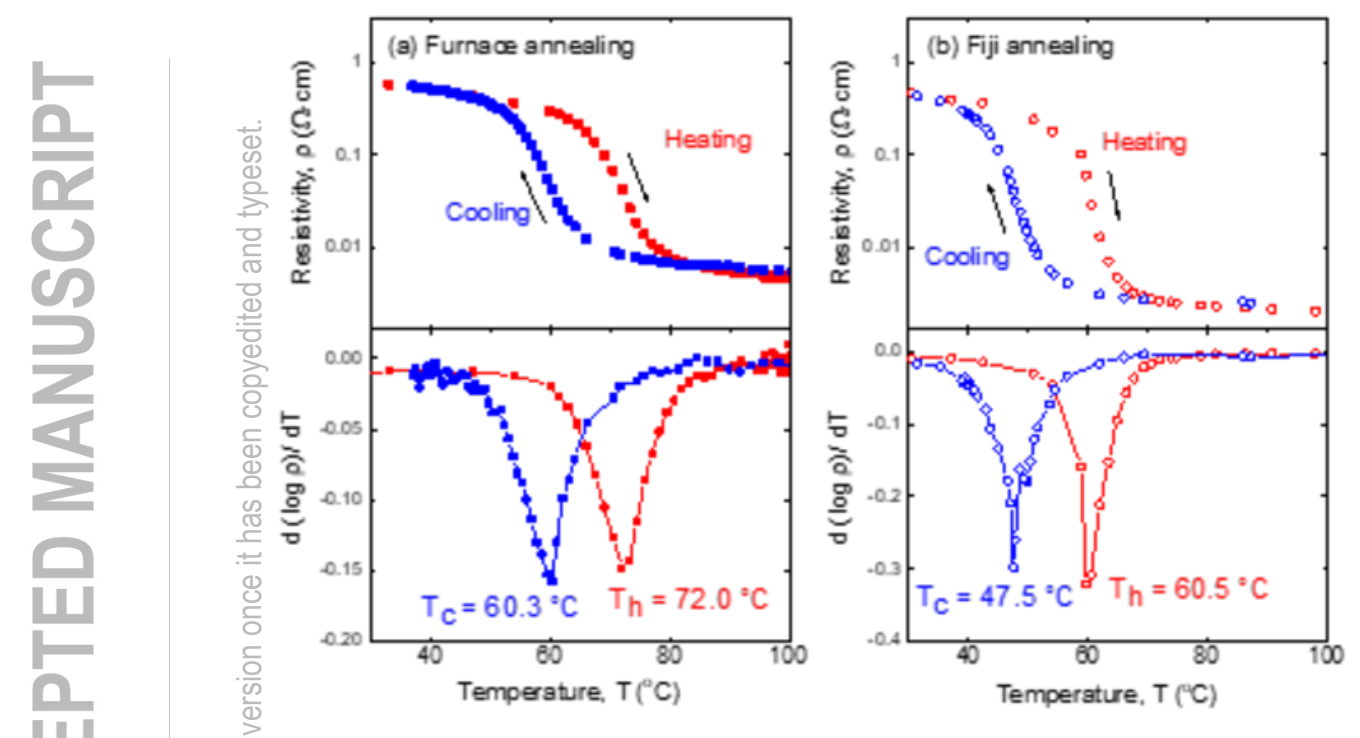

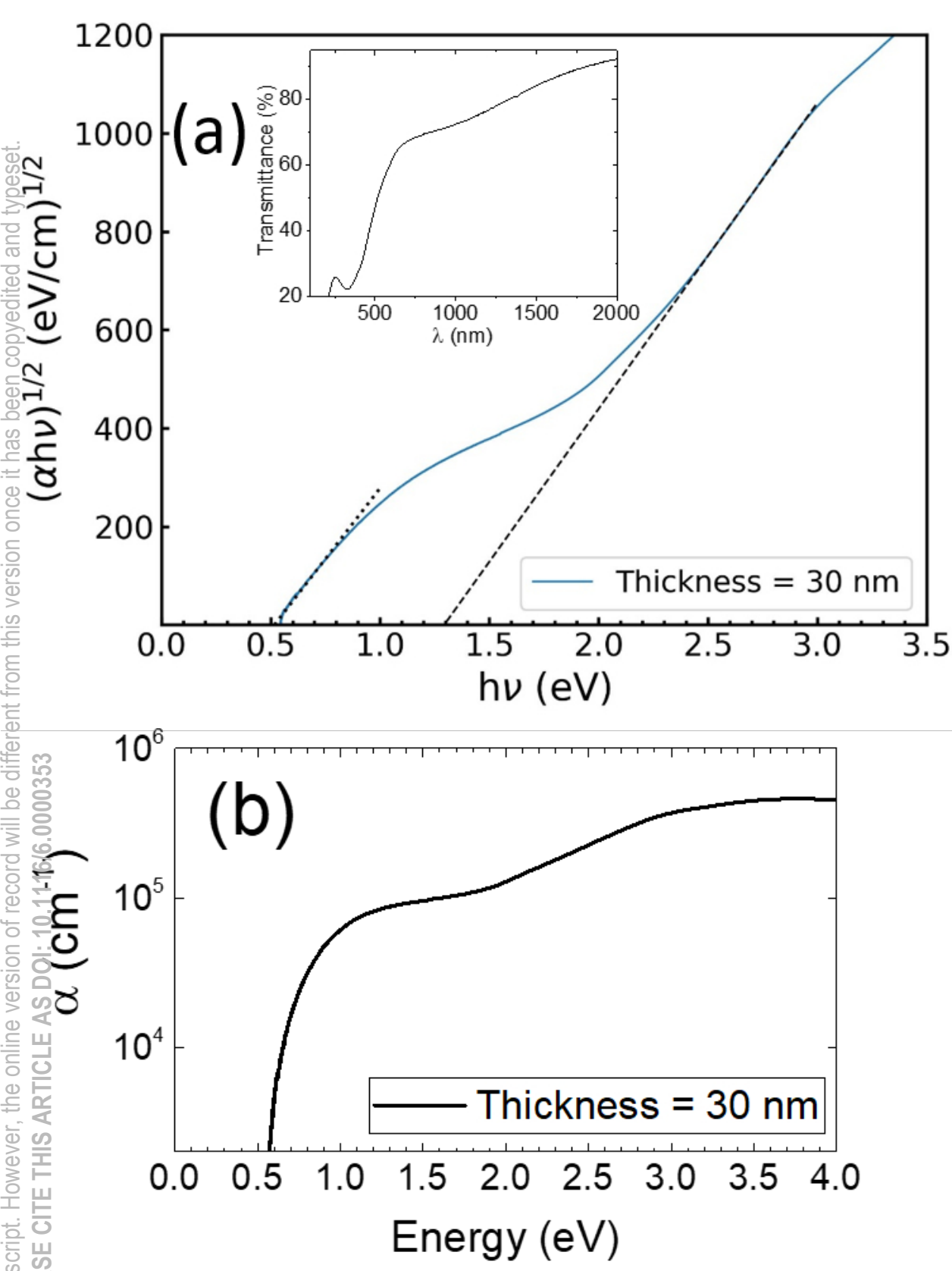
(a) vo2 in nm vs. Position

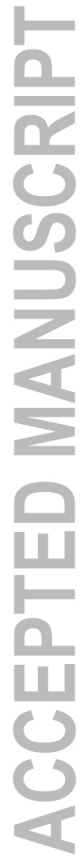

(b)

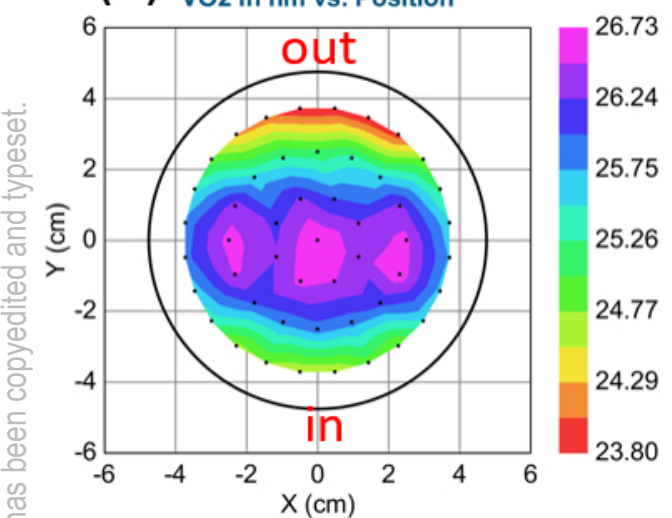

49.55

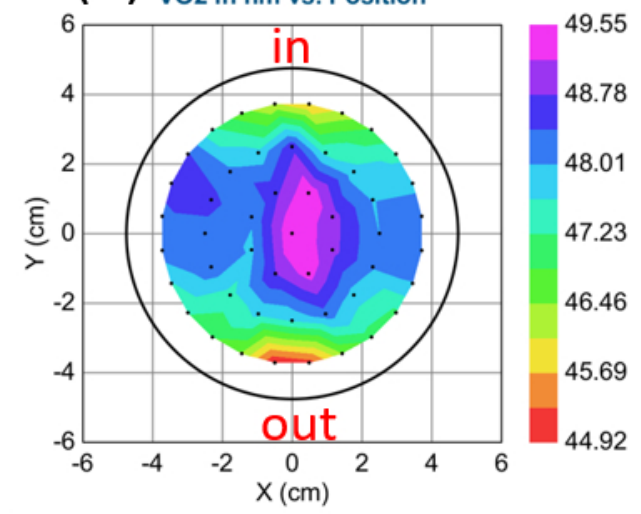

8.78

7.23

46.46

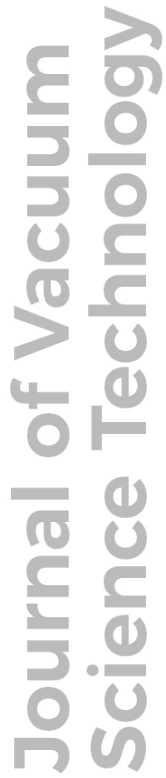

衰

층ㅇㅇㅇ

3 응

흘

음

응

(1)

든

등 는

닫 만

히롣

오 쁩

푸응

는

달 땀

ह 믐

엄

(9) 

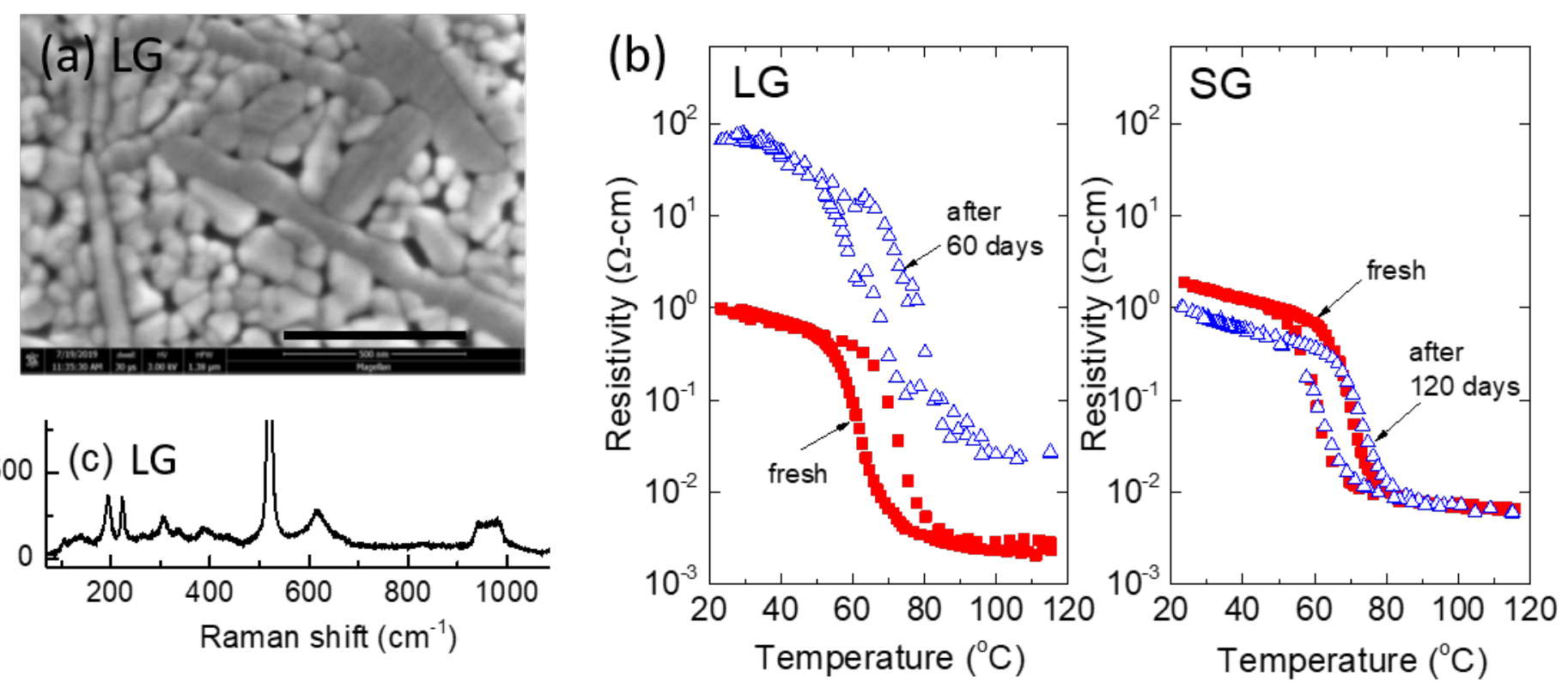